\title{
Changes in Density of Muscarinic Cholinergic Receptor by Adrenergic Denervation with Guanethidine
}

\author{
Hiroshi HIGUCHI, Miho MURATA, Shuji UCHIDA and Hiroshi YOSHIDA \\ Department of Pharmacology I. Osaka University School of Medicine. \\ Nakanoshima, Kita-ku. Osaka 530, Japan
}

Accepted November 19, 1984

\begin{abstract}
The effects of chronic adrenergic denervation with guanethidine on muscarinic cholinergic receptors (mAChR) were investigated by binding of $\mathrm{L}-{ }^{3} \mathrm{H}$ quinuclidinyl benzilate $\left({ }^{3} \mathrm{H}-\mathrm{QNB}\right)$. Guanethidine treatment decreased the amount of mAChR from 102 to 87 fmoles/mg protein in the heart and from 444 to 388 fmoles/mg protein in the small intestine, but increased it from 223 to 282 fmoles/ $\mathrm{mg}$ protein in the vas deferens, without changes in its characteristics. These findings suggested that adrenergic innervation has different influences on the mAChR population in different tissues.
\end{abstract}

The amount of muscarinic cholinergic receptor (mAChR) in various organs is regulated in vivo by many factors. One important factor is acetylcholine (ACh), an endogenous agonist released from parasympathetic nerve endings, that induces accelerated degradation of mAChR (1-4). Independently of $\mathrm{ACh}$, nerve growth factor (NGF) also was found to increase the amount of $\mathrm{mAChR}$ in the pheochromocytoma cell line PC12 (5).

Recently, chronic sympathetic denervation has also been reported to affect the amounts of mAChR in the salivary gland and heart of rats (6-8), smooth muscle of chicks $(9,10)$, and brain of mice (11). However. denervation of the adrenergic neuron resulted in increases in the amounts of mAChR in the salivary gland and smooth muscle and decreases in the amounts in the brain. In some organs (e.g., in the rat heart), the opposite effects of sympathetic denervation have been reported $(7,8)$. Therefore, findings on the effect of chronic sympathetic denervation seem to be discrepant. This discrepancy might be due to the differences of procedures of adrenergic denervation (mechanical surgery or treatment with 6hydroxydopamine).

To know more precisely the effect of sympathetic innervation on the amount of
mAChR in various tissues in vivo, we used chronic treatment with guanethidine, as another method of adrenergic denervation, which is known to destroy peripheral adrenergic neurons completely (12-17); and then we studied the resulting changes in the amounts of mAChR in the heart, small intestine, and vas deferens by measuring binding of ${ }^{3} \mathrm{H}$-quinuclidinyl benzilate (ONB).

Male CD strain rats (Charles River) weighing 180-200 g were treated with guanethidine by the method of Johnson and O'Brien (12, 15). Namely, they were given guanethidine $(40 \mathrm{mg} / \mathrm{kg} /$ day, i.p.) for five consecutive days a week for five weeks, as a solution of $5 \mathrm{mg} / \mathrm{ml}$ in isotonic saline adjusted to $\mathrm{pH} 7.4$, which was prepared just before injection. The same volume of isotonic saline was injected into control animals. The animals were killed four weeks after the last treatment, when Johnson and O'Brien and others showed remarkable decrease in norepinephrine content in heart, small intestine and vas deferens of the animals $(12,16,17)$. The heart and vasa deferentia were freed from the serosal coat with blood vessels and connective tissues and weighed. The longitudinal muscle from a $20 \mathrm{~cm}$ segment of ileum from the ileum end was weighed and freed of connective tissues. These organs were homogenized, as reported before (2-4). 
Binding of $\mathrm{L}-{ }^{3} \mathrm{H}-\mathrm{QNB} \quad(33.1 \mathrm{Ci} / \mathrm{mmol})$ was assayed at $37^{\circ} \mathrm{C}$ for $60 \mathrm{~min}$ in reaction medium $(2 \mathrm{ml}$ ) containing $50 \mathrm{mM}$ Tris- $\mathrm{HCl}$ $(\mathrm{pH} 7.4), 10 \mathrm{mM} \mathrm{MgCl} 2,1-4 \mathrm{mg}$ homogenized tissue and various concentrations of ${ }^{3} \mathrm{H}-\mathrm{QNB}$ and drugs. Bound ${ }^{3} \mathrm{H}-\mathrm{QNB}$ was separated from the medium by filtration on a Whatman GF/F filter, and its radioactivity was measured in a liquid scintillation counter. Specific binding was defined as the difference between the total binding and binding in the presence of $10^{-5} \mathrm{M}$ atropine. The Kiapp. values for $\mathrm{ACh}$ were corrected for the radioligand occupancy shift according to the equation Kiapp. $=1 C 50 /\left(1+L / K_{d}\right)$, where $K_{d}$ and $L$ represent the dissociation constant and the concentration of ${ }^{3} \mathrm{H}-\mathrm{QNB}$ (18).

Protein was determined by the method of Lowry et al. (19). Statistical analyses were made by Student's $t$-test, and a level of $\mathrm{P}<0.05$ was regarded as significant.

The following drugs were used: acetylcholine chloride (Nakarai), physostigmine salicylate and atropine sulfate (Sigma), guanethidine monosulphate (ismelin, CibaGeigy), guanyl-5'-yl imidodiphosphate $(\mathrm{Gpp}(\mathrm{NH}) \mathrm{p}$, Boehringer Mannheim), and $\mathrm{L}-{ }^{3} \mathrm{H}$-quinuclidinyl benzilate (QNB. New England Nuclear).

Figure 1 shows Scatchard analyses of ${ }^{3} \mathrm{H}$ QNB binding in the heart, small intestine and vas deferens. The lines are straight, indicating the presence of only one kind of binding site for QNB. After guanethidine treatment, Scatchard plots showed parallel shifts, indicating changes in the amount of receptor without change in its affinity for QNB. Administration of guanethidine decreased the $B_{\max }$ values of ${ }^{3} \mathrm{H}-\mathrm{QNB}$ in the heart and longitudinal muscle of the ileum to $85 \%$ and $87 \%$, respectively, of the control values (Fig. 1A, B). On the contrary, this treatment increased the $B_{\max }$ of ${ }^{3} \mathrm{H}-\mathrm{QNB}$ in the vas deferens to $126 \%$ of the control value. The results obtained by Scatchard analyses are summarized in Table 1A.

Chronic adrenergic denervation might affect the binding characteristics of agonists to $m A C h R$. There is a report of decrease in the affinities of agonists to $M A C h R$ in heart treated with 6-hydroxydopamine (7), but another report indicated no changes in the affinities of $m A C h R$ in brain when the amount of mAChR was decreased by treatment with 6 -hydroxydopamine (11)

Table $1 \mathrm{~B}$ shows results on the inhibition of ${ }^{3} \mathrm{H}-\mathrm{QNB}$ binding by $\mathrm{ACh}$. After guanethidine treatment, the apparent affinities of ACh to $\mathrm{mAChR}$ in the heart, small intestine, and vas deferens did not change, although the amounts of mAChR in these tissues did change. Gpp (NH)p, a GTP nonhydrolyzable analogue, reduced the apparent affinities of ACh to mACh in the heart, small intestine, and vas deferens, and guanethidine treatment did not influence the effect of $\mathrm{Gpp}(\mathrm{NH}) \mathrm{p}$ on
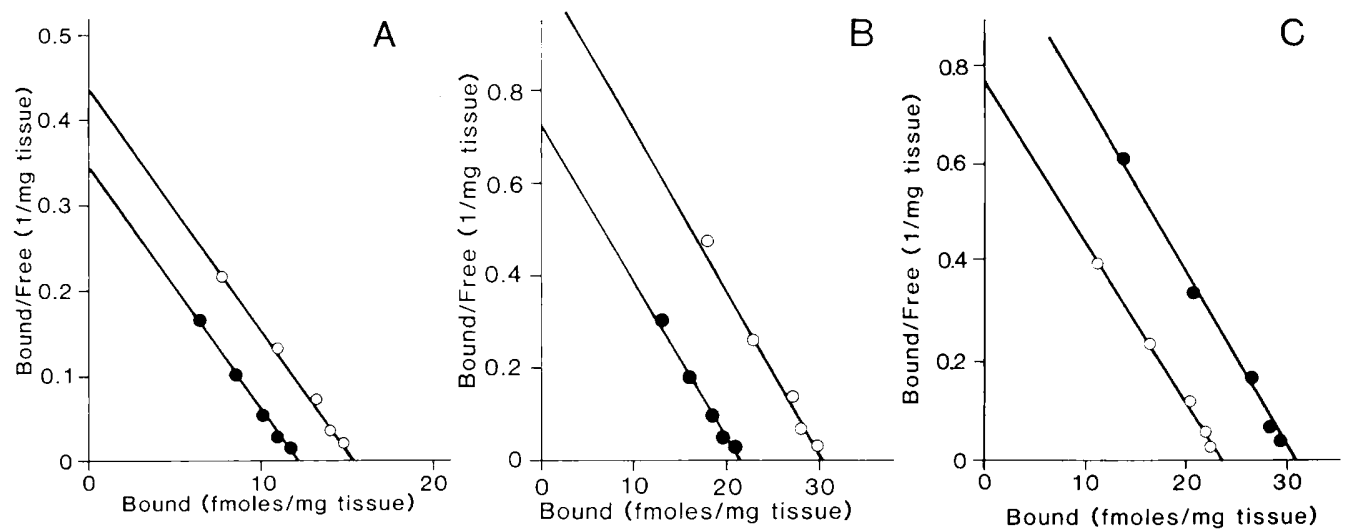

Fig. 1. Scatchard plots of specific ${ }^{3} \mathrm{H}$-QNB binding to preparations obtained from guanethidine-treated (O) and untreated $(\bigcirc)$ rats. Points are means for three separate experiments. Details of procedures are described in the Methods. A: heart, B: small intestine, $C$ : vas defereris. 
Table 1. Effect of guanethidine treatment on ${ }^{3} \mathrm{H}$-ONB binding in the heart, small intestine and vas deferens

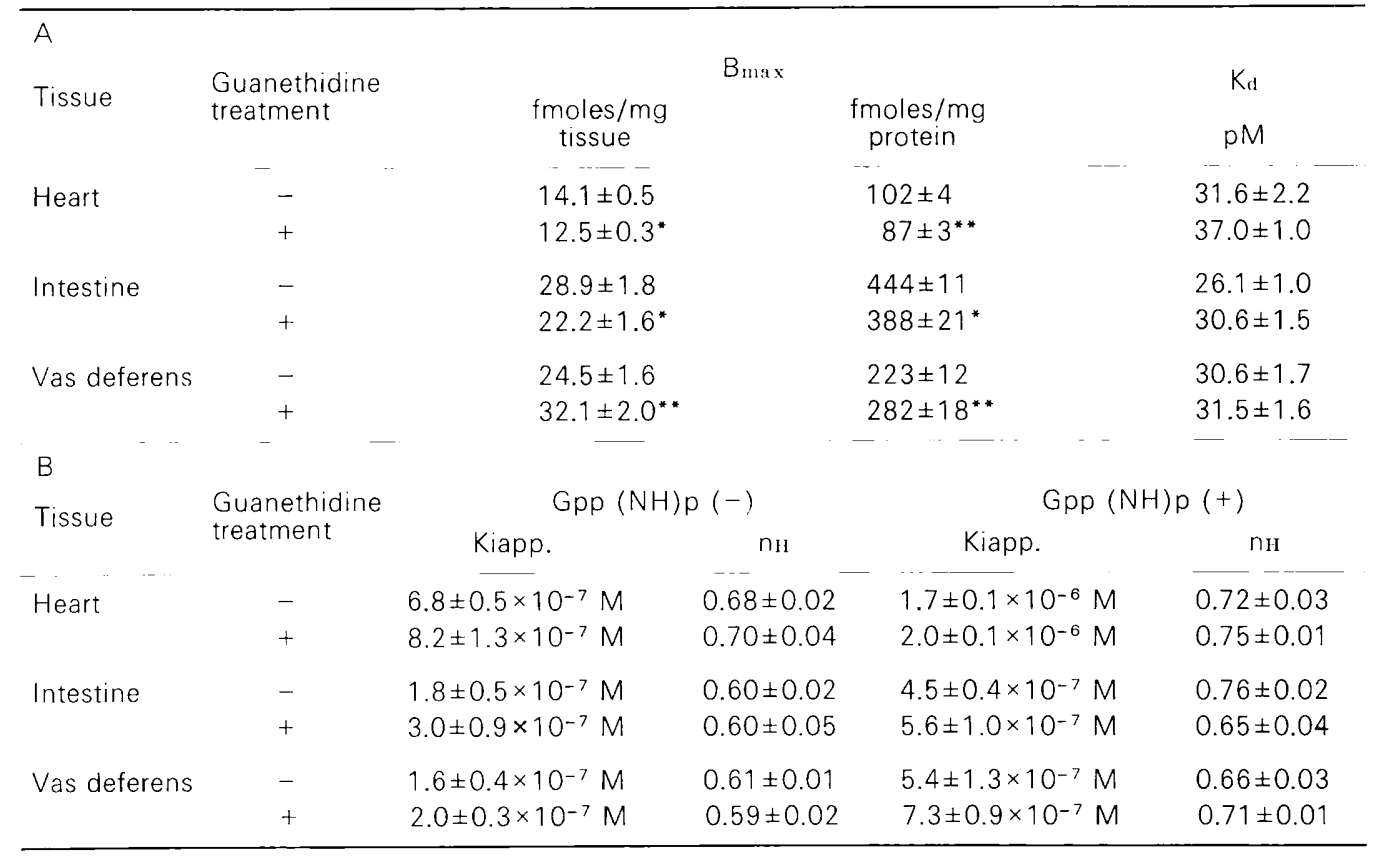

A. Values are means \pm S.E. for 6 separate experiments, each done in duplicate. Significance of differences from untreated tissues: ${ }^{*} P<0.05,{ }^{*}{ }^{*} P<0.025$.

B. Values are means \pm S.E. for 3 separate experiments, each done in duplicate. IC50 values for ACh determined from competition experiments were corrected to apparent $K_{i}$ (Kiapp.) values for $A C h$ using the Cheng and Prusoff equation (16). Hill's numbers ( $\left.n_{11}\right)$ were calculated from ACh displacement of $\left[{ }^{3} \mathrm{H}\right]$ - QNB $(0.9 \mathrm{nM})$ in the presence of $10^{-5} \mathrm{M}$ physostigmine. Differences between values with and without guanethidine treatment were not significant.

affinities of ACh to mAChR.

Chronic treatment with guanethidine, an adrenergic blocking agent that causes irreversible destruction of the peripheral sympathetic neuron system, can be used on adult animals $(12,13,15)$. Morphological studies have shown that the cytotoxic effects of guanethidine, characterized by dramatic swelling of the mitochondria, are specific for sympathetic neurons $(13,14,20)$. Furthermore, guanethidine did not seem to act directly on mAChR, because guanethidine did not inhibit the contraction to $A C h$ of rat vas deferens through $\mathrm{mAChR}$ in vitro, and the affinity of guanethidine to $\mathrm{mAChR}$ was very low. We used the method of Johnson and O'Brien $(12,15)$ for guanethidine treatment and investigated the effect of this chemical adrenergic denervation on the amount of mAChR. As shown in Fig. 1 and Table 1A. this treatment decreased the amounts of mAChR in the heart and small intestine, but increased the amount of mAChR in the vas deferens. Previous papers (6-11) have reported various effects of chemical adrenergic denervation with mechanical procedures or 6-hydroxydopamine treatment on the mAChR population. These findings and the present results suggest that adrenergic denervation has various influences on the mAChR populations in different tissues of the same body.

In the rat heart, inconsistent changes in mAChR density following 6-hydroxydopamine treatment have been reported ( 7 . $8)$. This difference is not explainable at present. However, in the present study, we found a slight but significant decrease in the specific binding of $3 \mathrm{H}-\mathrm{QNB}$ after guanethidine treatment, consistent with the data 
of Sharma and Banerjee (7). In the heart and small intestine of rats and the brain of mice. where the amount of mAChR was decreased by adrenergic denervation, mAChR may be located on adrenergic neurons, and their nerve terminals and so-called "presynaptic" mAChR may disappear after adrenergic denervation. This possibility is supported by the findings that reserpine treatment, which destroys the storage mechanisms for catecholamines and blocks sympathetic transmission without the degeneration of adrenergic nerve terminal, did not decrease the amount of mAChR in the heart or brain $(7,11)$.

In the salivary gland and vas deferens of rats and smooth muscle of chicken wing. where adrenergic denervation increased the mAChR population, regulation of $m A C h R$ by trophic factors may be considered. Nerve growth factor has been reported to increase the amount of mAChR in PC12 cells, but other factors may also participate in smooth muscles.

After guanethidine treatment, the affinities of ONB and ACh to mAChR were not changed in any of the tissues examined (Table 1B). Sharma and Banerjee (7) reported decreases in the affinities of agonists to mAChR after chemical adrenergic denervation with 6-hydroxydopamine and speculated that this change was due to a difference between presynaptic and postsynaptic mAChR. Therefore, we examined the binding characteristics of ${ }^{3} \mathrm{H}-\mathrm{QNB}$ after chronic adrenergic denervation with guanethidine. However, we could not detect any change in either the affinity of ACh to $\mathrm{mAChR}$ or the effect of $\mathrm{Gpp}(\mathrm{NH}) \mathrm{p}$ on the affinity of $\mathrm{ACh}$ after guanethidine treatment. This discrepancy may be due to the small extent of change in the amount of mAChR after guanethidine treatment. Alternatively, the difference between presynaptic and postsynaptic mAChR in affinities to muscarinic agonists and antagonists may be too small to detect in binding studies, as shown in the case of Gurwitz et al. (11).

\section{References}

1 Klein, W.L., Nathanson, N. and Nirenberg, M.: Muscarinic acetylcholine receptor regulation by accelerated rate of receptor loss. Biochem.
Biophys. Res. Commun. 90, 506-512 (1979)

2 Higuchi, H., Takeyasu, K., Uchida, S. and Yoshida, $\mathrm{H}$.: Receptor-activated and energydependent decrease of muscarinic cholinergic receptors in guinea-pig vas deferens. Eur. J. Pharmacol. 75, 305-311 (1981)

3 Higuchi, H., Takeyasu, K., Uchida, S. and Yoshida, $\mathrm{H}$.: Mechanism of agonist-induced degradation of muscarinic cholinergic receptor in cultured vas deferens of guinea-pig. Eur. J. Pharmacol. 79, 67-77 (1982)

4 Higuchi, H., Uchida, S., Matsumoto, K. and Yoshida, $H .:$ Inhibition of agonist-induced degradation of muscarinic cholinergic receptor by quinacrine and tetracaine-possible involvement of phospholipase $A_{2}$ in receptor degradation. Eur. J. Pharmacol. 94, 229-239 (1983)

5 Jumblatt, J.E. and Tischler, A.S.: Regulation of muscarinic ligand binding sites by nerve growth factor in PC12 pheochromocytoma cells. Nature 297, 152-154 (1982)

6 Pimoule, C., Briley, M., Arbilla, S. and Langer, S.Z.: Chronic sympathetic denervation increases muscarinic cholinoceptor binding in the rat submaxillary gland. Naunyn Schmiedebergs Arch. Prarmacol. 312, 15-18 (1980)

7 Sharma, V.K. and Banerjee, S.P.: Presynaptic muscarinic cholinergic receptors. Nature 272 , 276-278 (1978)

8 Yamada, S., Yamamura, H.I. and Roeske, W.R.: Alteration in cardiac autonomic receptors following 6-hydroxydopamine treatment in rats. Mol. Pharmacol. 18, 185-192 (1980)

9 Rush, R.A., Crouch, M.F., Morris, C.P. and Gannon, B.J.: Neural regulation of muscarinic receptors in chick expansor secundariorum muscle. Nature 296, 569-570 (1982)

10 Bennett, T., Lot, T.Y. and Strange, P.G.: The effects of noradrenergic denervation on muscarinic receptors of smooth muscle. Br. J. Pharmacol. 76, 177-183 (1982)

11 Gurwitz, D., Kloog, Y., Egozi, Y. and Sokolovsky, $M$.: Central muscarinic receptor degeneration following 6-hydroxydopamine lesion in mice. Life Sci. 26, 79-84 (1980)

12 Johnson, E.M. and O'Brien, F.: Evaluation of the permanent sympathectomy produced by the administration of guanethidine to adult rats. J. Pharmacol. Exp. Ther. 196, 53-61 (1976)

13 Burnstock, G., Evans, B., Gannon, B.J., Heath, J.W. and James, V.: A new method of destroying adrenergic nerves in adult animals using guanethidine. Br. J. Pharmacol. 43, 295-301 (1971) 
14 Angeletti, P.U., Levi-Montalcini, R. and Caramia, F.: Structural and ultrastructural changes in developing sympathetic ganglia induced by guanethidine. Brain Res. 43, 515-525 (1972)

15 Glaubiger, G., Tsai, B.S., Lefkowitz, R.J., Weiss, B. and Johnson, E.M.: Chronic guanethidine treatment increases cardiac-adrenergic receptors. Nature 273, 240-242 (1978)

16 Johnson, E.M., Cantor, E. and Douglas, J.R.: Biochemical and functional evaluation of the sympathectomy produced by the administration of guanethidine to newborn rats. J. Pharmacol. Exp. ther. 193, 503-512 (1975)

17 Grobecker, H., Roizen, M.F., Jacobowitz, D.M. and Kopin, I.J.: Effect of prolonged treatment with adrenergic neuron blocking drugs on sympathoadrenal reactivity in rats. Eur. J. Pharmacol. 46, 125-133 (1977)

18 Cheng, Y. and Prusoff, W.H.: Relationship between the inhibition constant $\left(K_{i}\right)$ and the concentration of inhibitor which causes 50 percent inhibition (IC50) of an enzymatic reaction. Biochem. Pharmacol. 22, 3099-3108 (1973)

19 Lowry, O.H., Rosebrough, N.J., Farr, A.L. and Randall, R.J.: Protein measurement with the Folin phenol reagent. J. Biol. Chem. 193, 265275 (1951)

20 Angeletti, P.V. and Levi-Montalcini, R.: Growth inhibition of sympathetic cells by some adrenergic blocking agents. Proc. Natl. Acad. Sci. U.S.A. 69, 86-88 (1972) 